\title{
Bisphosphonate-Related Osteonecrosis of the Jaw Bone: Radiological Pattern and the Potential Role of CBCT in Early Diagnosis
}

\author{
James Olutayo ${ }^{1,2}$, Jimoh Olubanwo Agbaje ${ }^{3}$, Reinhilde Jacobs', Vicky Verhaeghe ${ }^{3}$, Filip Vande \\ Velde $^{4}$, Frans Vinckier ${ }^{3}$ \\ ${ }^{1}$ Oral Imaging Center, Department of Dentistry, Oral Pathology and Maxillofacial Surgery, Faculty of Medicine, Catholic \\ University of Leuven, Leuven, Belgium \\ ${ }^{2}$ Department of Dentistry, Faculty of Clinical Sciences, University of Maiduguri, Maiduguri, Nigeria \\ ${ }^{3}$ Department of Paediatric Dentistry and Special Dental Care, School of Dentistry, Oral Pathology and Maxillofacial Surgery, \\ Faculty of Medicine, Catholic University of Leuven, Leuven, Belgium \\ ${ }^{4}$ Private Periodontologist, Antwerp, Belgium.
}

\author{
Corresponding Author: \\ James Olutayo \\ Department of Dentistry, Faculty of Clinical Sciences \\ University of Maiduguri \\ P.M.B. 1069, Maiduguri \\ Nigeria \\ E-mail: olutayo.james@gmail.com
}

\begin{abstract}
Objectives: To systematize the clinico-radiological symptoms and course of bisphosphonate-related osteonecrosis of jaw bone and to evaluate the diagnostic potential of various radiological techniques to detect mild osteonecrosis in each stage of the disease.

Material and Methods: The sample consisted of 22 patients previously diagnosed with extraoral malignant disease. Diagnosis was based on a clinical examination in conjunction to digital panoramic radiography and cone beam computed tomography (CBCT). Two dentomaxillofacial radiologists reviewed all images.

Results: Twenty patients showed mandibular involvement clinically, while two others had a maxillary involvement. Four stages of the disease were proposed based on the clinico-radiological findings. Subclinical cortical and lamina dura thickening was detected with only three-dimensional CBCT and periapical images, while ulceration and cortical bone thickening was detected only by three-dimensional CBCT. Mixed sclerotic, lytic bone destruction involving alveolar and basal bone with or without encroachment on the mandibular canal, pathological mandibular fractures were detected by two-dimensional panoramic and three-dimensional CBCT images. Other findings are non healing extraction sockets, periapical radiolucencies, osteolysis, sequestra, oroantral fistula, and periosteal new bone formation.

Conclusions: The present study showed that bisphosphonate-related osteonecrosis of jaw bone occurs in four distinct clinicoradiological stages. For mild cases, panoramic image diagnosis was much less obvious, whereas cone beam computed tomography was able to fully characterise the bony lesions and describe their extent and involvement of neighbouring structures in all cases. Thus cone beam computed tomography might better contribute to the prevention of bisphosphonaterelated osteonecrosis of jaw bone as well to the disease management.
\end{abstract}

Keywords: bisphosphonates; jaw; osteonecrosis; cone-beam CT; early diagnosis.

Accepted for publication: 30 March 2010

To cite this article:

Olutayo J, Agbaje JO, Jacobs R, Verhaeghe V, Velde FV, Vinckier F. Bisphosphonate-Related Osteonecrosis of the Jaw Bone: Radiological Pattern and the Potential Role of CBCT in Early Diagnosis.

J Oral Maxillofac Res 2010 (Apr-Jun);1(2):e3

URL: http://www.ejomr.org/JOMR/archives/2010/2/e3/e3ht.pdf

doi: $10.5037 /$ jomr.2010.1203 


\section{INTRODUCTION}

The relationship between intravenous bisphosphonate administration and jaw bone osteonecrosis was first reported in 2003 [1]. It is defined as an area of exposed bone in the maxillofacial region for more than eight weeks in a patient who was receiving a bisphosphonate and had not had radiation therapy to the craniofacial region [2]. It is often denoted as bisphosphonate-related osteonecrosis of the jaw (BRONJ). This describes a spectrum of intraoral symptoms, especially seen in cancer patients treated with high levels of intravenous bisphosphonates.

Bisphosphonates are non-metabolic synthetic analogues of pyrophosphate which have potent inhibitory effects on bone resorption [ 3 ]. They are the drugs of choice in prevention and treatment of bone disorders characterised by increased bone resorption, such as Paget's disease, osteoporosis, hypercalcaemia of cancer, multiple myeloma and bony metastases [3].

Though there is abundant evidence in the literature of the benefit of bisphosphonates therapy, growing evidence from several recently published reports show that patients treated with bisphosphonates have a potential risk of develop necrosis of the jaw bone [4-10].

The diagnosis of BRONJ is currently based on the patients' medical history of bisphosphonate treatment and clinical evaluation (pain, bone exposure, purulent secretion or swelling). The initial appearance of the disease is variable and thus, it often comes to the attention of the clinician late, when BRONJ has become symptomatic.

The role of imaging in the diagnosis of BRONJ and the imaging findings has previously been described in the literature [11], but no distinct clinico-radiological systematization of the disorder has been reported.

Recently, several cone beam computed tomography (CBCT) systems have become available, which are specifically designed to image hard tissues in the maxillofacial region [14].

This results in new diagnostic possibilities with increased diagnostic image quality. With the available CBCT systems, high-contrast structures can be visualized at very low radiation doses, sometimes as low as two panoramic radiographs [15]. Such CBCT data might therefore help to define the radiological range of appearances of BRONJ.

The purpose of the present study was to systematize the clinico-radiological symptoms and course of bisphosphonate-related osteonecrosis of jaw bone and to create guidelines for the most optimal radiological examination methods in each stage of the disease.

\section{MATERIAL AND METHODS}

\section{Patient recruitment}

A series of 22 subjects ( 17 males and 5 females, age range $54-87$ years, mean age 69.2 years) with a diagnosis of osteonecrosis development in the jaw bone(s) were consecutively recruited from the patient sample visiting the Department of Paediatric and Special Dental Care, School of Dentistry, Oral Pathology and Maxillofacial Surgery, Faculty of Medicine, Leuven between October 2007 and March 2008. They all had undergone a biophosphonate treatment based on a previous diagnosis of extraoral malignant disease. All patients gave their informed consent to participate in the study, in accordance with the ethical regulations of the University Hospitals, Catholic University of Leuven.

Nine patients had multiple myeloma, 6 prostate cancer, 3 breast cancer and 4 renal cell cancer. All patients had been treated with either individual intravenous doses of zoledronate or pamidronate and were therefore at risk for developing BRONJ. The diagnosis of BRONJ was confirmed through the clinical evaluation of the exposed bone to the oral cavity in addition to the negative history of radiotherapy to the head and neck.

The presenting symptoms: the localization of the necrosis, the presence of suppuration and the association with previous extractions or traumas as possible triggering factor for the onset of the lesions were documented in all patients.

\section{Radiological examination}

As part of a routine clinical examination, a digital panoramic radiograph was taken using a Cranex Tome ${ }^{\mathbb{B}}$ (Soredex, Tuusula, Finland) and the CBCT of the jaws was obtained using a SCANORA $3 \mathrm{D}^{\circledR}$ CBCT unit (Soredex, Tuusula, Finland). The CBCT device uses complementary metal-oxide semiconductor (CMOS) flat panel/CsI detector and is operated at $85 \mathrm{kV}$ and 13 $\mathrm{mA}$, with a full jaw scan with a $75 \times 145 \mathrm{~mm}$ field of view for a single $360^{\circ}$ rotation.

Primary reconstruction of the data provided 1.0 $\mathrm{mm}$ axial, coronal, and sagittal slices (300 - 500 slices) as well as the three-dimensional volumetric surface renderings. The data set had a voxel size of $0.25 \times 0.25 \times 0.25 \mathrm{~mm}$ and consisted of contiguous slices with respect to the $\mathrm{Z}$-axis. These were reconstructed secondarily to provide a curved planar two-dimensional multiplanar reconstruction (MPR) $20 \mathrm{~mm}$ thick along the arch of the mandible that provides a simulated "panoramic" equivalent. Panoramic reconstruction at narrower defined "focal trough" limits (such as 
$5-10 \mathrm{~mm}$ ) better depicted the degree of involvement and extent of margins in a projection that was still crosssectional imaging at $1 \mathrm{~mm}$ thick slices, and in $1 \mathrm{~mm}$ slice increments also provided orthogonal views to the panoramic curved planar view. Previous radiographs of the patients were also retrieved and correlated with the present ones for possible changes.

The radiographs and $\mathrm{CBCT}$ images were evaluated by two dentomaxillofacial radiologists under standardized viewing conditions $(40 \mathrm{~cm}$ viewing distance, diagnostic screen, dimmed room). Calibration was done beforehand to reduce the intra- and inter-examiner variability regarding the following variables: imaging characteristics of the alveolar and basal bone (lytic/ erosive, sclerotic, and mixed), presence of sequestrum, cortical discontinuity, periosteal response, involvement of vital structures (e.g. the mandibular canal and maxillary antrum) and soft tissues involvement. Four stages of the disease progression were proposed based on the clinico-radiological findings.

\section{RESULTS}

Demographic data are presented in Table 1. In most patients, the lesions initially occurred after dental extraction. The body of the mandible was the predominant clinical site of involvement in all the patients. Area of necrosis was discovered on the CBCT image of the mandible in one of the patients with an extensive necrosis of the maxilla.

The staging of the disorder was done based on the clinico-radiological findings (Table 2).

The least changes at first presentation were observed in patients with radiological evidence of osteosclerosis involving the cortical bone, alveolar margin and lamina dura but with clinically intact mucosa and no oral symptoms or discomfort (stage I). This radiological finding was only detected using the periapical radiographs and CBCT (Figures 1 and 2).

In stage II, ulceration was located in the posterior/

Table 1. Patients data

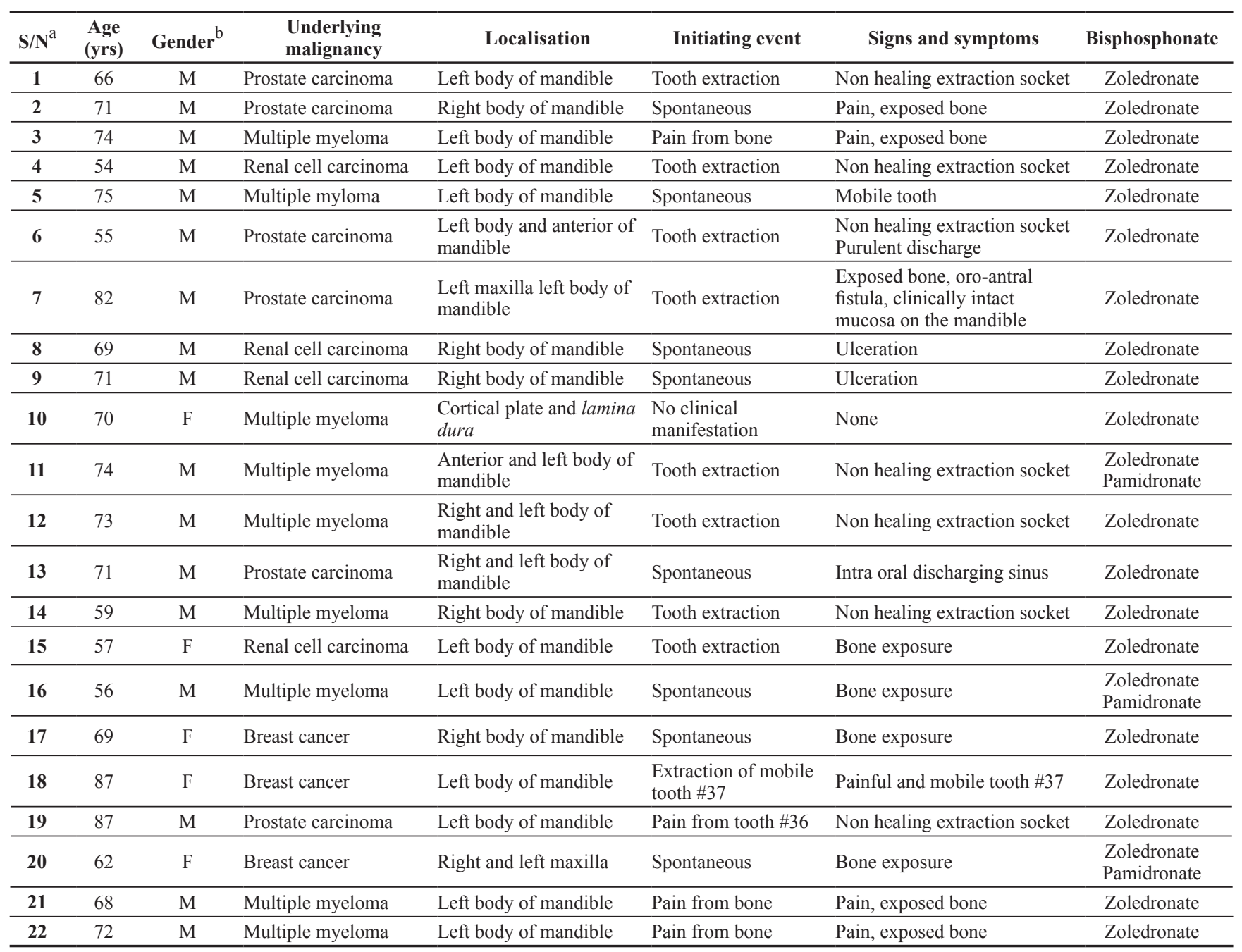

${ }^{\mathrm{a}} \mathrm{S} / \mathrm{N}=$ serial numbers.

${ }^{\mathrm{b}} \mathrm{M}=$ male; $\mathrm{F}=$ female. 
Table 2. Summary of the clinical and radiologic findings, classified according to different stages and manifestations of the disease

\begin{tabular}{clll}
\hline Stage & N & \multicolumn{1}{c}{ Clinical presentation } & \multicolumn{1}{c}{$\begin{array}{c}\text { Radiological findings } \\
\text { examination method }\end{array}$} \\
\hline I & 2 & None & $\begin{array}{l}\text { Generalised thickening of cortical plate and lamina dura, focal area } \\
\text { of sclerosis extending from cortical plate }\end{array}$ \\
\hline II & 2 & $\begin{array}{l}\text { Discomfort, denuded bone in the } \\
\text { posterior/lingual mandible }\end{array}$ & Thickening of cortical plate \\
\hline III & 14 & $\begin{array}{l}\text { Pain, denuded bone involving alveolar } \\
\text { bone }\end{array}$ & $\begin{array}{l}\text { Mixed sclerotic and lytic bone destruction involving alveolar bone } \\
\text { and basal bone, sequestrum }\end{array}$ \\
\hline IV & 4 & $\begin{array}{l}\text { Denuded bone involving alveolar } \\
\text { bone, purulent discharge, numbness, } \\
\text { oro-antral fistula }\end{array}$ & $\begin{array}{l}\text { Mixed sclerotic and lytic bone destruction involving alveolar and } \\
\text { basal bone, sequestrum, encroachment on the mandibular canal and } \\
\text { maxillary antrum, pathologic fracture }\end{array}$ \\
\hline
\end{tabular}
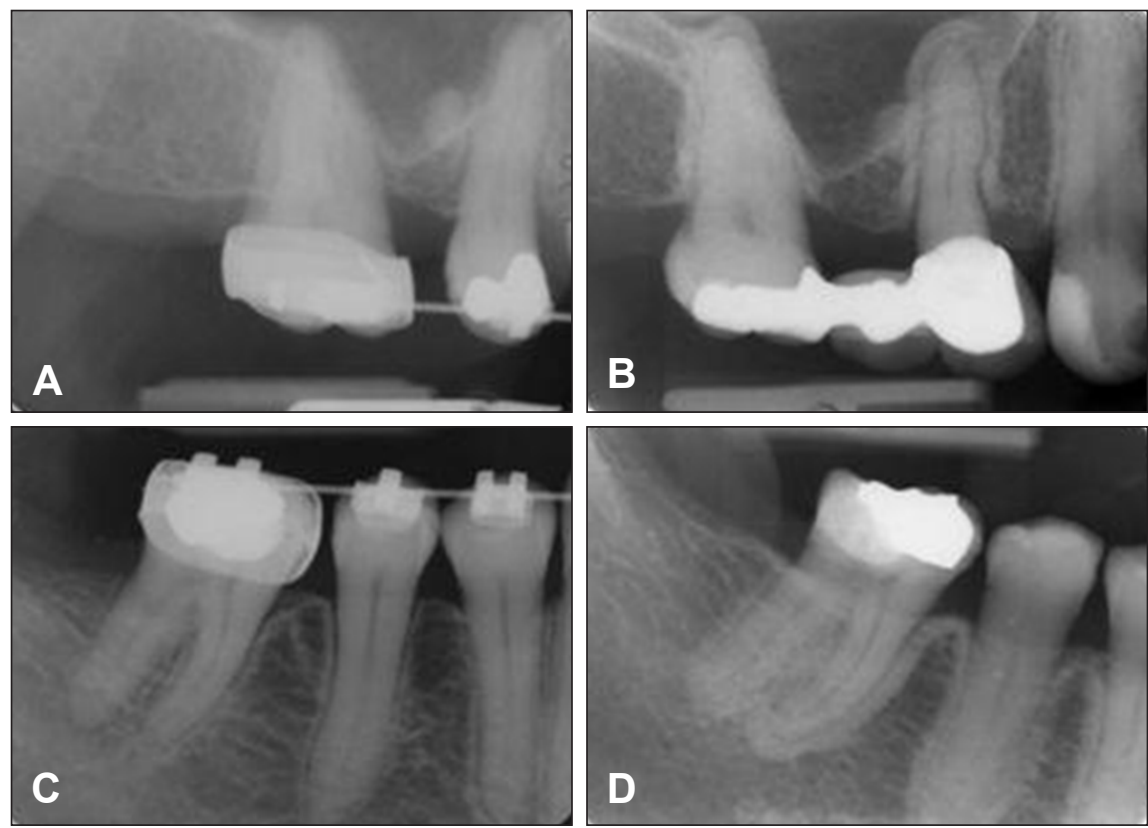

Figure 1. Periapical radiographs of a 71 years old woman (patient number 10), showing generalized osseous sclerosis of uniform thickness involving the cortical plate and lamina dura. A and $\mathrm{C}$ radiographs shows the pre-bisphosphonate therapy condition of the cortical plates and the lamina dura. B and D radiographs shows thickening of the cortical plate and lamina dura after 2 years bisphosphonate therapy. No clinical signs and symptoms were established at this initial stage.
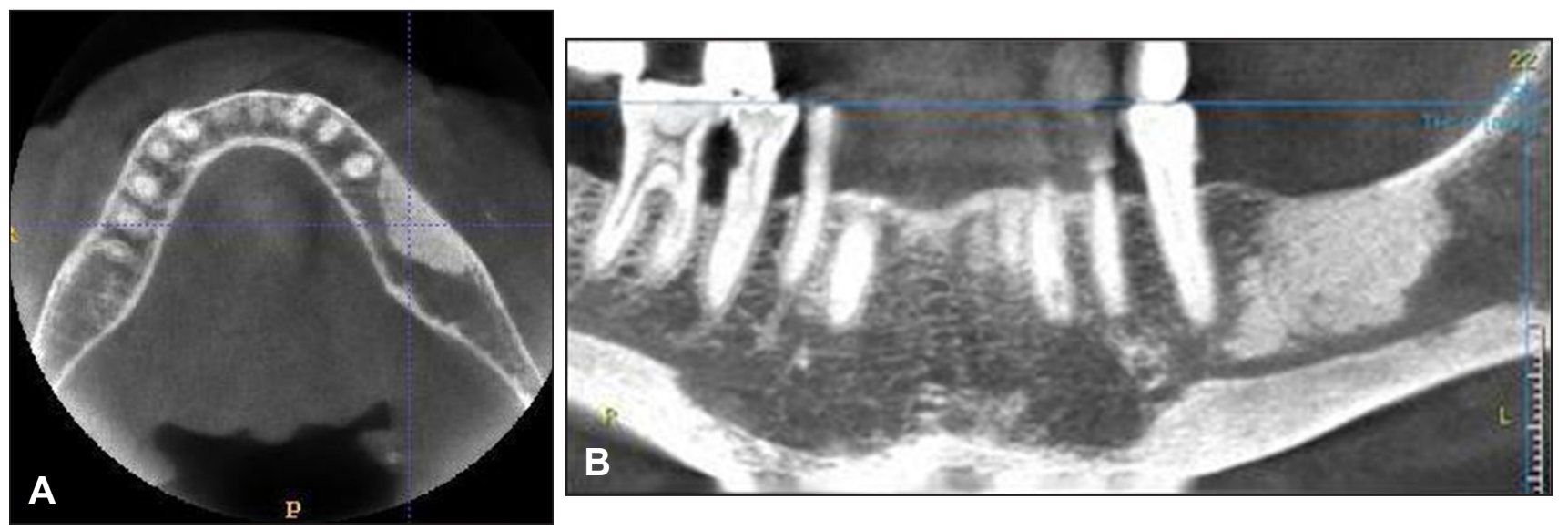

Figure 2. $A=$ Axial images of the mandible obtained with Scanora $3 \mathrm{D}^{\circledR} \mathrm{CBCT}$ unit showing thickening of cortical plate and focal region of medullary bone density on the left body of mandible, the overlying mucosa is clinically intact.

$\mathrm{B}=$ Two-dimensional multiplanar reconstruction image showing the vertical dimension of the region of osteosclecrosis and the relationship with mandibular canal. 
lingual mandible in the area of the mylohyoid ridge, the exposed bone surface was smooth and patients presented with discomfort as the tongue constantly rub on the ulceration. Thickening of the cortical plate in the affected region was the only radiological findings on CBCT.

Panoramic radiographs did not yield obvious evidence of the disease status in stage I and II of the disease

\section{(Table 2).}

Increases in sclerotic manifestations correlated with a more sever expression of BRONJ in stage III and IV lesions were detected on both imaging modality, yet much more pathologic characteristics and the entire lesion extent could be visualized on CBCT (Table 2) (Figures 3-5).
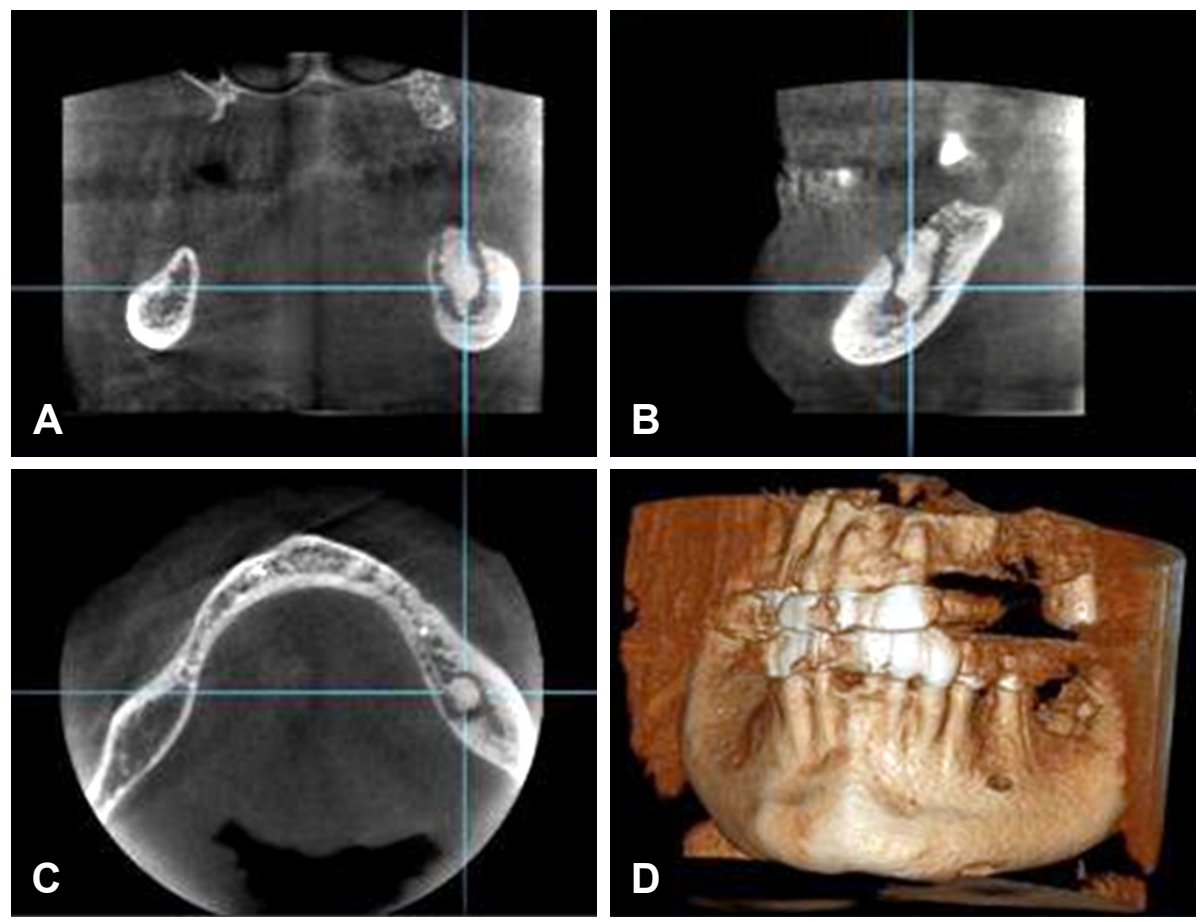

Figure 3. $\mathrm{A}=$ coronal, $\mathrm{B}=$ sagital, $\mathrm{C}=$ axial and $\mathrm{D}=$ three-dimensional images of the mandible obtained with Scanora $3 \mathrm{D}^{\circledR}$ CBCT unit showing region of extensive necrosis in a 71 years old patient. Centrally, a well demarcated bony sequestrum is evident, involving the upper border of the mandibular canal.
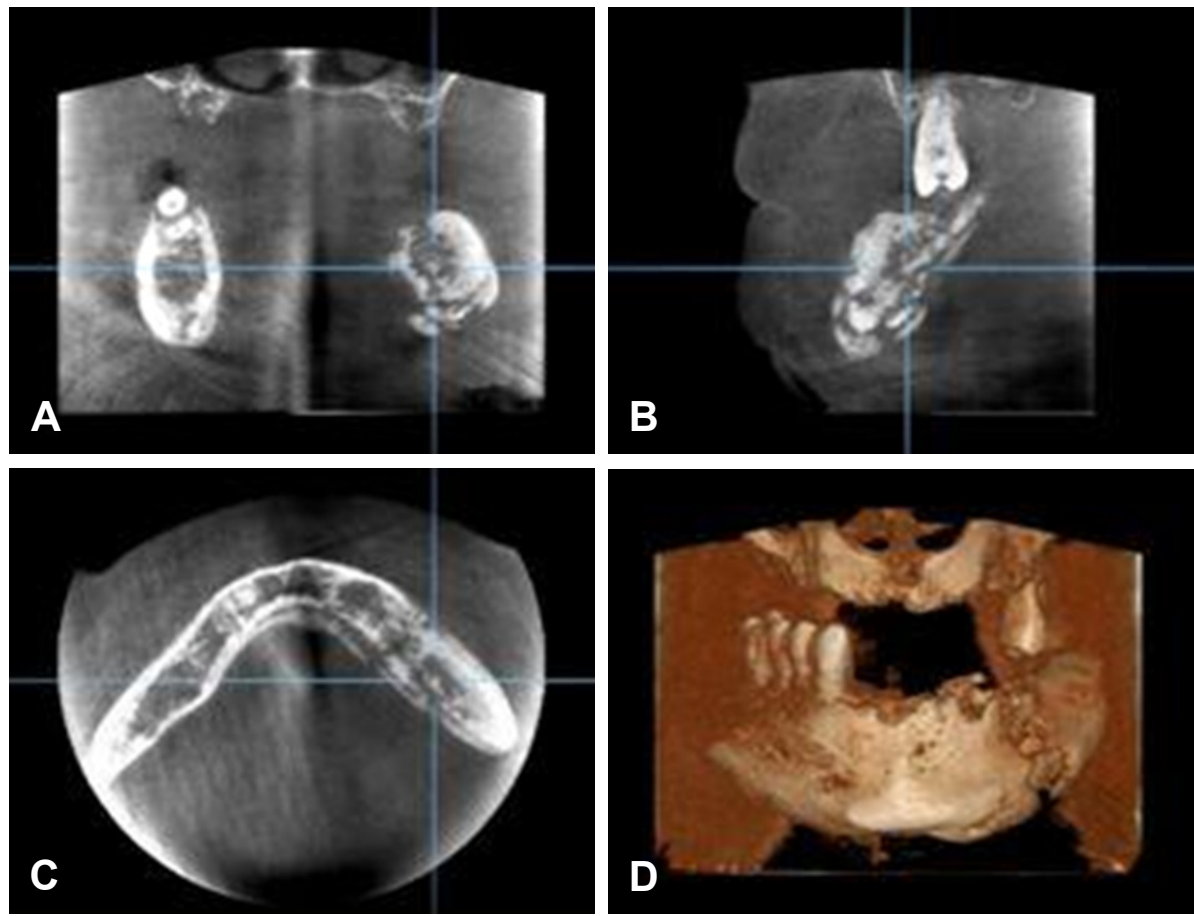

Figure 4. $\mathrm{A}=$ coronal, $\mathrm{B}=$ sagital, $\mathrm{C}=$ axial and $\mathrm{D}=$ three-dimensional images of the mandible obtained with Scanora $3 \mathrm{D}^{\circledR} \mathrm{CBCT}$ unit with region of extensive necrosis and pathological fracture of the mandible. 

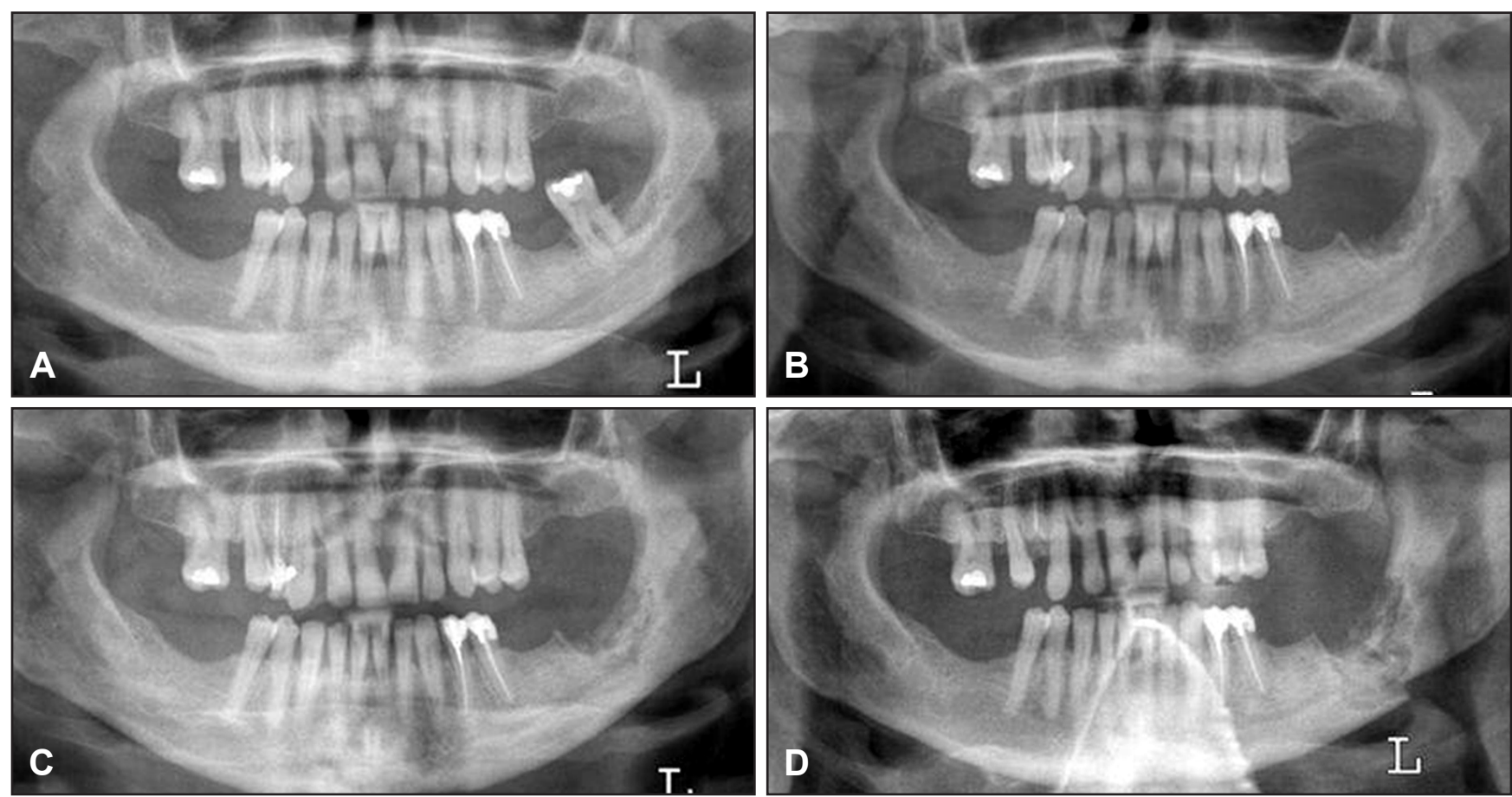

Figure 5. $\mathrm{A}=$ Panoramic radiograph of an 87 years old woman (patient number 18) with breast cancer treated with zoledronate who presented with a painful tooth \#37.

$\mathrm{B}=$ Panoramic radiograph after 7 months, showing non healing extraction site in the left posterior mandible, absence of bone remodeling and sclerotic bone changes of the body of the mandible.

$\mathrm{C}=$ Panoramic radiograph after 9 months demonstrates a nonhealing extraction site in the left posterior mandible with progressive sclerosis of the left body and angle of the mandible with encroachment on the left mandibular canal.

$\mathrm{D}=$ Panoramic radiograph after 19 months with intervening curettage, demonstrates progression of sclerosis to pathologic fracture of the mandible.

\section{DISCUSSION}

A major limitation of this study is the small sample size; however the data presented was representative of the various clinico-pathologic manifestation of BRONJ. Bisphosphonate-related necrosis of jaw bone remains a challenge with respect to diagnosis and management. This presents a growing concern for oral health care workers since the disorder appears almost exclusively in the jaws $[4,7,16]$. This is because the diagnosis is made at the late stage when there is bone exposure to the oral cavity. Standard diagnosis based on clinico-radiological criteria is still lacking and there are no clinico-radiological guidelines for the clinicians to follow. Bone exposure often occurred spontaneously or after dental extractions or oral trauma with progression to sequestration associated with purulent discharge and in some cases fistula formation $[\underline{4}, \underline{8}, \underline{17}]$. Most reported cases of necrosis of the jaws associated with bisphosphonate use involve the recent nitrogen-containing injectable bisphosphonates such as pamidronate and zoledronate $[\underline{1}, \underline{8}, \underline{18}]$. Incidentally, all patients in this study were treated with this group of bisphosphonates.

The pathogenesis of BRONJ remains unclear however, many theories have been proposed by various authors $[\underline{4}, \underline{6}]$. Most cases of osteonecrosis in this study occurred in the posterior alveolar region of the mandible where the cortical bone is thickest. The reason for this has been attributed to the high bisphosphonates concentration in the region as a result of high drug uptake and high bone turnover due to constant mastication. $[11,19]$ This condition is said to inhibit osteoclastic activity, thereby decreasing bone remodeling and predisposing the bone to accumulated micro-damage, potentially causing the onset of osteonecrosis.

The most common clinical finding in this series is an area of ulcerated mucosa with exposed devitalized bone. In all patients with exposed necrotic bone, the observed area of ulceration was smaller with wider area of underlying bone necrosis as previously reported by Bedogni et al. [20]. This makes imaging mandatory in assessing the extent of the lesion.

In the patients with least changes, the lesion presented as a linear sclerosis of uniform thickness limited to the alveolar margin and the lamina dura (Figure 1), while a focal area of sclerosis was detected on the CBCT of the mandible of the other patient who only had bony exposure on the maxilla (Figure 2). Both patients had intact oral mucosa and did not present with any oral symptoms or discomfort in the sclerotic region. 
This mild involvement represents the stage I of the disorder. This can easily be detected with periapical radiograph since the bone changes are still limited to the periapical region. Indeed, active bone resorption has been reported to be absent at this early stage $[\underline{6}, \underline{10}]$, CBCT provided a good view of this early discrete and subtle bone changes (Figure 2).

Avoiding invasive procedures and institution of preventive measures at this bone pre-exposure stage may delay the clinical progress and possibly provide an environment conducive to resolution of the condition. Patients with stage II of the disease had an area of ulceration at the posterior/lingual mandible in the area of the mylohyoid ridge with no apparent radiological changes on the panoramic view but presents as cortical thickening on the CBCT. This region had earlier been reported as one of most common site of BRONJ [ [ ] ]. The ulceration might have been due to the pressure effect of the tongue on the elevated ridge and the bone reaction may still be limited to the periosteum at this stage.

Diagnosis at these vital stages may give room for prompt implementation of the preventive measure recommended for BRONJ in the literature $[\underline{4}, \underline{6}, \underline{7}]$ and adequate follow-up to check the progression of the disease.

Panoramic radiograph may not be useful in the diagnosis of this early lesssion because of its limited resolution, two-dimensional nature with anatomic overlap and tomographic effect which may not allow visualization of the true extent of the bone defects. The present finding correlate well with those earlier described by Arce et al. [12].

Patients with a more advanced stage of the disease presented with bone exposure to the oral cavity at previous tooth extraction sites $[\underline{8}, \underline{13}]$. The exposed bone had a grayish discoloration with irregular surface, which on probing was asymptomatic and avascular. These findings were consistent with avascular osteonecrosis and similar to the documented findings in literature $[1, \underline{6}, 8]$. The panoramic radiograph in this group of patient showed an area of sclerosis with some radiolucency with poorly defined margin. CBCT was able to provide detailed information about characteristics and extent of the cortical and trabecular bone involvement and the proximity of the alteration in the bony architecture to vital structure such as mandibular canal (Figure 3).

In most severe cases, Stage IV the CBCT and the panoramic radiograph now revealed larger areas of osseous sclerosis involving the entire cross-sectional area of the jaw in all cases, with sclerotic changes encroached on the mandibular canal and the maxillary antrum. Devitalized bone with radiodense appearance and radiolucent rim (Figure 3) denoting bone sequestration were also predominant at this advanced stage of the disease (Figures 3 and 4), while pathologic fracture of the mandible was observed in two patients (Figures 4 and 5).

In all the patients, necrosis involved the alveolar margin and the cortical plate, in line with the findings reported by Phal et al. [11]. This suggests that BRONJ possibly originates in the cortical or alveolar bone with a progression towards the medulla.

CBCT imaging allowed high resolution hard tissue diagnosis, and when offering a field of view, covering both jaws, affected areas could be easily compared to non-affected areas while asymptomatic area can also be detected.

Furthermore, the CBCT data could also be considered valuable for volumetry which helps to determine the extent of the disease. As such it can serve as a guide towards management planning. Indeed, cross-sectional slices allowed identification of the true extent of affected marrow and thus facilitated transfer from the three-dimensional images to the surgical topographical landmarks and vice versa.

The observed radiological characteristics suggests a distinct pattern of occurrence and progress of BRONJ, starting from the lamina dura and cortical plate, to involve the alveolar bone and then progress to enter the medullar bone, and finally the entire cross-sectional area of the jaw bone. This sequence is confirmed in subjects with image follow-up over time; showing that the destructive bone changes were often progressive (Figures 1 and 5).

While routine jaw imaging for patients receiving bisphosphonate therapy may not be justified, it is essential that oral health care providers rule out such early bone changes, when a patient at risk presents with a need for jaw bone imaging. This may allow for early diagnosis, better treatment and prevention of new potential case as this can make a significant difference in the outcome of the disease.

\section{CONCLUSIONS}

The present study showed that bisphosphonate-related osteonecrosis of jaw bone occur in four distinct clinicoradiological stages. For mild cases, panoramic image diagnosis was much less obvious. Whereas cone beam computed tomography was able to fully characterise the bony lesions and describe their extent and involvement of neighbouring structures in all cases. Thus cone beam computed tomography might better contribute to the prevention of bisphosphonate-related osteonecrosis of jaw bone as well to disease management. 


\section{ACKNOWLEDGMENTS AND DISCLOSURE STATEMENTS}

The authors report no conflicts of interest related to this

study.

\section{REFERENCES}

1. Marx RE. Pamidronate (Aredia) and zoledronate (Zometa) induced avascular necrosis of the jaws: a growing epidemic. J Oral Maxillofac Surg. 2003 Sep;61(9):1115-7. [Medline: 12966493] [doi: 10.1016/S0278-2391(03)00720-1]

2. Khosla S, Burr D, Cauley J, Dempster DW, Ebeling PR, Felsenberg D, Gagel RF, Gilsanz V, Guise T, Koka S, McCauley LK, McGowan J, McKee MD, Mohla S, Pendrys DG, Raisz LG, Ruggiero SL, Shafer DM, Shum L, Silverman SL, Van Poznak CH, Watts N, Woo SB, Shane E; American Society for Bone and Mineral Research. Bisphosphonate-associated osteonecrosis of the jaw: report of a task force of the American Society for Bone and Mineral Research. J Bone Miner Res. 2007 Oct;22(10):1479-91. [Medline: 17663640] [doi: 10.1359/jbmr.0707oni]

3. Kimmel DB. Mechanism of action, pharmacokinetic and pharmacodynamic profile, and clinical applications of nitrogen-containing bisphosphonates. J Dent Res. 2007 Nov;86(11):1022-33. Review. [Medline: 17959891] [doi: $10.1177 / 154405910708601102$ ]

4. Marx RE, Sawatari Y, Fortin M, Broumand V. Bisphosphonate-induced exposed bone (osteonecrosis/osteopetrosis) of the jaws: risk factors, recognition, prevention, and treatment. J Oral Maxillofac Surg. 2005 Nov;63(11):1567-75. [Medline: 16243172] [doi: 10.1016/j.joms.2005.07.010]

5. Melo MD, Obeid G. Osteonecrosis of the jaws in patients with a history of receiving bisphosphonate therapy: strategies for prevention and early recognition. J Am Dent Assoc. 2005 Dec;136(12):1675-81. [Medline: 16383049] [FREE Full Text]

6. Migliorati CA, Schubert MM, Peterson DE, Seneda LM. Bisphosphonate-associated osteonecrosis of mandibular and maxillary bone: an emerging oral complication of supportive cancer therapy. Cancer. 2005 Jul 1;104(1):83-93 [Medline: 15929121] [doi: 10.1002/cncr.21130] [FREE Full Text]

7. Migliorati CA, Siegel MA, Elting LS. Bisphosphonate-associated osteonecrosis: a long-term complication of bisphosphonate treatment. Lancet Oncol. 2006 Jun;7(6):508-14. Review. Erratum in: Lancet Oncol. 2006 Jul;7(7):533. [Medline: 16750501 ] [doi: 10.1016/S1470-2045(06)70726-4]

8. Ruggiero SL, Mehrotra B, Rosenberg TJ, Engroff SL. Osteonecrosis of the jaws associated with the use of bisphosphonates: a review of 63 cases. J Oral Maxillofac Surg. 2004 May;62(5):527-34. [Medline: 15122554] [doi: $10.1016 /$ j.joms.2004.02.004]

9. Ruggiero SL, Fantasia J, Carlson E. Bisphosphonate-related osteonecrosis of the jaw: background and guidelines for diagnosis, staging and management. Oral Surg Oral Med Oral Pathol Oral Radiol Endod. 2006 Oct;102(4):433-41. Epub $2006 \mathrm{Jul}$ 31. [Medline: 16997108] [doi: 10.1016/j.tripleo.2006.06.004]

10. Ruggiero SL, Drew SJ. Osteonecrosis of the jaws and bisphosphonate therapy. J Dent Res. 2007 Nov;86(11):101321. Review. Erratum in: J Dent Res. 2007 Dec;86(12):1223. [Medline: 17959890] [doi: 10.1177/154405910708601101] [FREE Full Text]

11. Phal PM, Myall RW, Assael LA, Weissman JL. Imaging findings of bisphosphonate-associated osteonecrosis of the jaws. AJNR Am J Neuroradiol. 2007 Jun-Jul;28(6):1139-45. [Medline: 17569974] [doi: 0.3174/ajnr.A0518] [FREE Full Text]

12. Arce K, Assael LA, Weissman JL, Markiewicz MR. Imaging findings in bisphosphonate-related osteonecrosis of jaws. J Oral Maxillofac Surg. 2009 May;67(5 Suppl):75-84. [Medline: 19371818] [doi: 10.1016/j.joms.2008.12.002]

13. Chiandussi S, Biasotto M, Dore F, Cavalli F, Cova MA, Di Lenarda R. Clinical and diagnostic imaging of bisphosphonateassociated osteonecrosis of the jaws. Dentomaxillofac Radiol. 2006 Jul;35(4):236-43. [Medline: 16798918] [doi: $10.1259 / \mathrm{dmfr} / 27458726$ ]

14. Fullmer JM, Scarfe WC, Kushner GM, Alpert B, Farman AG. Cone beam computed tomographic findings in refractory chronic suppurative osteomyelitis of the mandible. Br J Oral Maxillofac Surg. 2007 Jul;45(5):364-71. Epub 2006 Nov 13. [Medline: 17097778] [doi: 10.1016/j.bjoms.2006.10.009]

15. Schulze D, Blessmann M, Pohlenz P, Wagner KW, Heiland M. Diagnostic criteria for the detection of mandibular osteomyelitis using cone-beam computed tomography. Dentomaxillofac Radiol. 2006 Jul;35(4):232-5. [Medline: 16798917] [doi: 10.1259/dmfr/71331738]

16. Lo JC, O'Ryan FS, Gordon NP, Yang J, Hui RL, Martin D, Hutchinson M, Lathon PV, Sanchez G, Silver P, Chandra M, McCloskey CA, Staffa JA, Willy M, Selby JV, Go AS; Predicting Risk of Osteonecrosis of the Jaw with Oral Bisphosphonate Exposure (PROBE) Investigators. Prevalence of osteonecrosis of the jaw in patients with oral bisphosphonate exposure. J Oral Maxillofac Surg. 2010 Feb;68(2):243-53. Epub 2009 Sep 24. [Medline: 19772941] [doi: 10.1016/j.joms.2009.03.050] 
17. Vahtsevanos K, Kyrgidis A, Verrou E, Katodritou E, Triaridis S, Andreadis CG, Boukovinas I, Koloutsos GE, Teleioudis Z, Kitikidou K, Paraskevopoulos P, Zervas K, Antoniades K. Longitudinal cohort study of risk factors in cancer patients of bisphosphonate-related osteonecrosis of the jaw. J Clin Oncol. 2009 Nov 10;27(32):5356-62. Epub 2009 Oct 5. [Medline: 19805682] [doi: 10.1200/JCO.2009.21.9584]

18. Merigo E, Manfredi M, Meleti M, Corradi D, Vescovi P. Jaw bone necrosis without previous dental extractions associated with the use of bisphosphonates (pamidronate and zoledronate): a four-case report. J Oral Pathol Med. 2005 Nov;34(10):613-7. [Medline: 16202082] [doi: 10.1111/j.1600-0714.2005.00351.x]

19. Zahrowski JJ. Bisphosphonate treatment: an orthodontic concern calling for a proactive approach. Am J Orthod Dentofacial Orthop. 2007 Mar;131(3):311-20. Review. [Medline: 17346585]

20. Bedogni A, Saia G, Ragazzo M, Bettini G, Capelli P, D’Alessandro E, Nocini PF, Lo Russo L, Lo Muzio L, Blandamura S. Bisphosphonate-associated osteonecrosis can hide jaw metastases. Bone. 2007 Dec;41(6):942-5. Epub 2007 Aug 29. [Medline: 17905677] [doi: 10.1016/j.ajodo.2006.09.035]

\section{To cite this article:}

Olutayo J, Agbaje JO, Jacobs R, Verhaeghe V, Velde FV, Vinckier F. Bisphosphonate-Related Osteonecrosis of the Jaw Bone: Radiological Pattern and the Potential Role of CBCT in Early Diagnosis.

J Oral Maxillofac Res 2010;1(2):e3

URL: http://www.ejomr.org/JOMR/archives/2010/2/e3/e3ht.pdf

doi: $10.5037 /$ jomr.2010.1203

Copyright (C) Olutayo J, Agbaje JO, Jacobs R, Verhaeghe V, Velde FV, Vinckier F. Accepted for publication in the JOURNAL OF ORAL \& MAXILLOFACIAL RESEARCH (http://www.ejomr.org), 30 March 2010.

This is an open-access article, first published in the JOURNAL OF ORAL \& MAXILLOFACIAL RESEARCH, distributed under the terms of the Creative Commons Attribution-Noncommercial-No Derivative Works 3.0 Unported License, which permits unrestricted non-commercial use, distribution, and reproduction in any medium, provided the original work and is properly cited. The copyright, license information and link to the original publication on (http://www.ejomr.org) must be included. 